\title{
Business processes engineering for organizing the construction objects' design
}

\author{
Olga Fil* \\ Don State Technical University, 344010, Rostov-on-Don, Russia
}

\begin{abstract}
The article is devoted to the engineering of business processes for organizing project activities. Engineering of the design organization aims to develop, introduce the new methods and model business processes for planning activities, carry out the engineering surveys, search for the most optimal design solutions that will achieve the best quality, taking into account all possible potential design problems. The author examines the scheme of business processes for organizing the design of construction projects, which will improve the development quality of design and estimate documentation and the applied design solutions' level.
\end{abstract}

\section{Introduction}

In connection with the large volumes of construction documentation development of buildings and structures, the relevance of such a line of activity as engineering of business processes is also growing. Unlike usual operational management, the task of which is to monitor compliance with the schedule for organizing design work, business process is engineering support at all stages of a construction facility design, including preparatory, design and expertise in order to reduce the time required for the development of design estimates with by promptly obtaining information that makes it possible to organize control of project activities.

\section{Materials and methods}

The digital technologies introduction ensures the quality of the project documentation development and a reduction in labor costs for project operations. There is currently a high rate of information technologies in design activities development, but at the same time a low level of modern, original engineering solutions' implementation in the field of technology, engineering systems, building structures, structures of technological units $[1,2]$. As a result of the projected design solutions, defects are revealed during construction and installation and commissioning, as well as during the facilities operation. The quality of design estimates in terms of the original technical solutions' development leads to a decrease in capital costs, an increase in the level of industrial and environmental safety of production facilities and is reflected in the profit during the facility operation due to the

\footnotetext{
*Corresponding author: oafil@yandex.ru
} 
saving of energy resources.

All this led to the necessity and expediency of developing a diagram of business processes for organizing a construction object design.

When developing and testing the scheme of business processes of project activities, the author adhered to the following defining provisions:

First, the scheme was based on the concept of a fair system of interaction between the customer - design institute - contractor;

Second, the possible degree of design solutions in a single information space is taken into account;

Third, to control the adopted design decisions' quality, a systematic approach is introduced in the design work organization.

Based on these positions, the author has developed and tested a diagram of the business processes of project activities (Figure 1).

For the management tools' digitalization, it is intended to implement the scheme of "business processes" (elementary structural units of the task). For the correct execution of the sequence of actions, a scenario in which each project goes through the same steps to achieve the expected results is used. The logic of this business process diagram corresponds to the project execution process division into the stages. Moreover, such a scheme has many branches and logical blocks with the involvement of specialists from different departments with different functionalities, as well as with varying responsibility degrees. For each action performance, a director, a performer (person in charge) and a deadline are appointed. Timely and correct execution of "business processes" directly affects the system of sanctions of the responsible person. The project manager is obliged to control the implementation of all project tasks, the correctness of the timing of their implementation, check the applicability of solutions, as well as their compliance with the basic design standards (GOST 21.1101, GOST 21.501, SPDS, the rules for design and working documentation, etc.) $[3,4]$. If a technical control specialist detects violations, the action and the task will be rejected and returned for revision, indicating the time frame for correction.

The business process diagram of project activities includes six stages: work with the customer, conceptual study of the project, project development, project examination, preparation and provision of the project, completion of work on project activities.

The first stage of the scheme includes three steps:

- Negotiations with the customer (Action -1);

- Preparation of a draft contract (Action-2);

- Formation of a database (Action-3a) and signing an agreement (Action-3b).

At the stage of "negotiations with the customer", various preparatory (pre-design) works can be implemented: inspection of buildings and structures, geological and geodetic surveys, aerial photography, assessment of the environment and infrastructure, economic justification of enlarged models. 


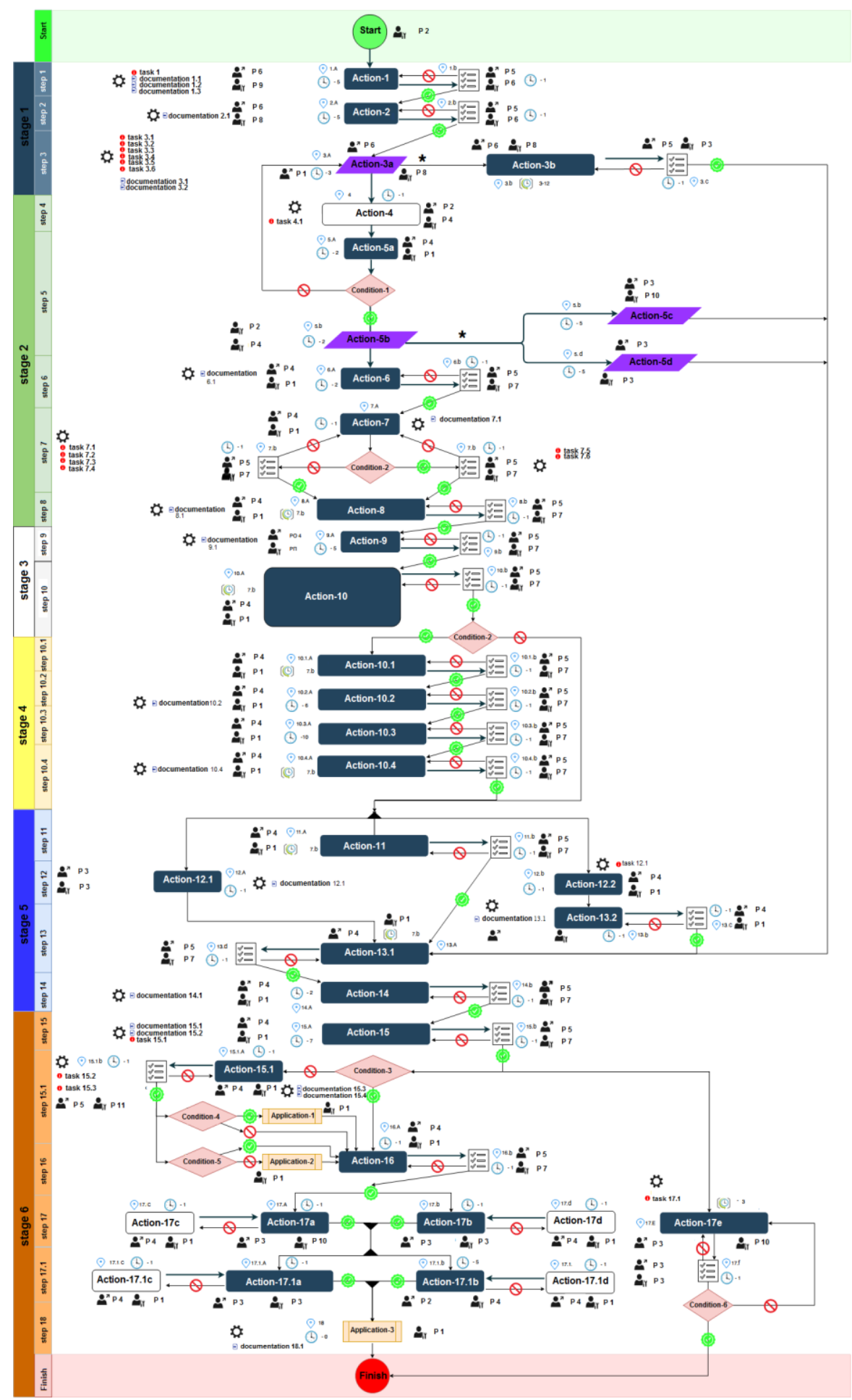

Fig.1. Diagram of business processes for organizing a construction object design

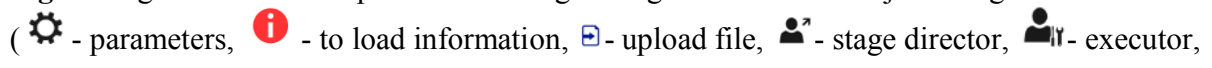


圈 - control, $Q$ - does not match, - - corresponds to, (1) - due date (working days),

- $\quad$ - the number of the step at which the due date is assigned, $\boldsymbol{\star}_{\text {- related tasks, }} \odot$ - step number,

- $\quad$ P1 - project manager, P2 - deputy director for technical part, P3 - deputy director for development, P4 - head of technical department, P5 - head of technology department, P6 - head of promotion department, P7 - technical control specialist, P8 - specialist contract department, P9 customer service technician, P10 - accountant, P11 - lawyer)

However, at this stage, characteristic problems can often be observed. Basic projects, reuse projects, as well as standard projects, on which the technical level of the solutions laid down in the project documentation depends, as well as the timing for its development, are not always correctly evaluated in terms of labor intensity and the ability to implement complex technical solutions by the organization or by engaging third-party performers and do not always differ in novelty, rationality and quality [5-7]. For this reason, at the stage of negotiations and contractual relations consolidation, in which the terms and volumes of the provided documentation appear, systemic and fundamental (in terms of the influence degree on the entire project) errors often arise, which are subsequently leveled both legally and economically. At this stage, a cash gap situation may arise. Thus, the income part does not always exceed the expenditure part by the amount planned at the beginning of work.

In order to minimize the impact of the above-mentioned problems, at the initial stage of the deal, a document called "Calculator" is formed. In the course of the calculation, the main items of expenditure required for the project implementation are determined, as well as the percentages of income and expenditure parts. Advance planning, even before the signing of the contract, makes it possible to avoid an incorrect assessment of the required resources on the part of the company. Moreover, such a calculation achieves transparency in relation to the project financial component: direct project managers have the opportunity not to make mistakes when involving outside specialists in the process of developing design and estimate documentation.

"Calculator" sums up structured information with division into the component parts of any project. This method of budgeting makes it possible to work out each project with high quality from start to finish, as well as get a sample of a particular project profitability.

A fairly large number of organizations in the industry do not have a budgeting system. Lack of understanding of the project cost and revenue side within the reporting period leads to overspending of resources where there is no need for it and to a lack of funds in the key, most critical components of the project. Budgeting is carried out at the start of the project for all persons responsible for the full design cycle. At the final project stage, the results are summed up according to the plan-fact scheme. A systematic approach to the organization of design, reconstruction and construction processes is a key task in management [8-10].

When negotiating with the customer, it is necessary to take into account the following requirements:

- informational, which include the formation of a folder of a construction object on the server (task 1);

- uploading to the generated folder on the server originals of documents such as the draft of the technical task (documentation 1.1), the calculator of the design work cost (documentation 1.2), the schedule of design work (documentation 1.3).

The result of the stage "negotiations with the customer" is the approval of the draft contract (documentation 2.1).

When signing the contract up, it is necessary to take into account the following requirements:

- informational, which include the approval of the name of the design object (task 3.1), the traffic organization scheme (task 3.2), the list of technological documentation (task 3.3), 
the deadline for the completion of work under the contract (task 3.4), the deadline for receiving the original contract (task 3.5), the procedure settlements under the contract (task 3.6).

- document management, including receipt of the customer's enterprise card (documentation 3.1) and a scanned copy of the signed contract (documentation 3.2).

The second stage of the business process diagram for organizing the construction object design includes five steps:

- Appointment of a project manager (Action-4);

- Study of the provided information about the project (Action-5a); loading the data into the glider (Action-5b), loading the data into 1-C (Action-5c), loading the data into the register list (Action-5d);

- Query of primary source data (Action-6);

- Preparation of a work plan (Action-7);

- Formation and coordination of basic conceptual solutions (Action-8).

When appointing a project manager, it is necessary to be guided by the list of employees whose qualifications meet the requirements of the position of the chief project engineer (task 4.1).

As a result of the requests submission, sufficient-necessary primary documentation is collected, on the basis of which the construction object design is carried out (documentation 6.1).

When preparing the work plan, it is necessary to take into account the following requirements:

- informational such as the deadline for the work on the formation and approval of the main conceptual solutions (task 7.1), the deadline for the work on the development of the project documentation sections (task 7.2), the deadline for the work on the working documentation preparation (task 7.3), the deadline for the work on the preparation of documentation to be handed over to the customer (task 7.4), the deadline for the preparation of documents for submission to the expertise (task 7.5), the deadline for the work to support the expertise (task 7.6);

- formation of the project activities' workflow through the approval and coordination of the work schedule (documentation 8.1).

To eliminate the possibility of making false technical decisions, the stage "Conceptual study" was introduced into the business process diagram. During this stage, the main conceptual solutions in terms of the territory and buildings planning, the materials used, the main solutions for engineering networks must be agreed. This function is assigned to the project manager. The logic of work is violated, since the project manager is not a specialist in all of the above-mentioned areas. Accordingly, he needs the technical support of all design specialists in the preliminary solutions development. The project manager can make a decision at the stage of the project conceptual study, which is contrary to the design standards, the possibility of their implementation at the facility, taking into account all local characteristics. At this stage, it is difficult to take into account possible intersections of design solutions of all specialists who will develop design and estimate documentation in the future.

At the "Conceptual study" stage the project manager studies the Agreement and the Terms of Reference, contacts the customer, receives the primary initial data from him (USRN statements, technical passport, certificates of balance sheet ownership of engineering networks), develops a work plan, a schedule for the development of sections.

As part of the "conceptual study", the project manager loads the documents with a work plan and a schedule for their implementation into the object folder. In accordance with these terms, the key tasks of "business processes" are formed.

After the stage "conceptual development" is the stage " sections development". Based 
on the agreed conceptual solutions from the number of selected specialists, the tasks for the execution of sections, according to the design specification are set.

The third stage of the scheme of business processes for organizing the design of a construction object includes:

- selection and approval of a group of performers (Action-9), by approval of the working group (documentation 9.1);

- development of documentation sections (Action-10).

For the project manager at this stage, it is important not to miss a single type of work, so that the project is developed in a holistic manner and is filled with everything that the customer would like to see. If the project provides for a small number of sections being developed, then it is possible to coordinate and take into account the work in a timely manner. But, if the project provides for a large number of sections being developed, a large amount of work on each of them, then occasional errors occur, the loss of some work in the documentation. To solve this problem, the project manager needs to keep his own log of decisions that need to be implemented within the project.

The fourth stage of the business process diagram for organizing the design of a construction object includes the following steps:

- preparation of documentation for submission to expert examination (Action-10.1);

- submission of documentation for expert examination (Action-10.2) under a concluded project expert appraisal agreement (documentation 10.2);

- analysis of expert comments (Action-10.3);

- support of the expertise (Action-10.4) with obtaining a positive conclusion of the project expertise (documentation 10.4).

After receiving a positive expert opinion, the development of the working documentation sections is underway, and then the project is transferred to the customer.

The fifth stage of the business process diagram for organizing the construction object design includes the following steps:

- preparation of working documentation (Action-11);

- preparation of a review (Action-12.1);

- preparation of an interim report from the chief engineer of the project (Action-12.2) with the determination of the date of formation of the act of completed work (task 12.1);

- project provision (Action-13.1);

- preparation of the completion certificate (Action-13.2) and invoicing for payment (documentation 13.1)

- provision of the project to the customer (Action-14) according to the transfer acceptance certificate (documentation 14.1).

After receiving the project, the customer signs an act of the project documentation acceptance and transfer, an act of completed work and receives an invoice for payment for the design and estimate documentation development services.

The sixth stage of the business processes diagram for organizing the design of a construction object includes the following steps:

- obtaining a full package of documents (Action-15);

- formation of an archive for the construction object design documentation (Action-16), provided that the work is completed on time according to the plan (Condition-3),

- generating a report (documentation 15.3) with an attachment (documentation 15.4) on the reasons for exceeding the deadlines (Action-15.1) with an analysis of the submitted documents compliance (Condition-4, task 15.2), and the submitted documents sufficiency (Condition-5), with systematic data entry (Application-1) and automatic generation of penalties for failure to meet deadlines (Application-2);

- control of reporting documentation (Action-17a) with the necessary adjustments (Action-17c); 
- control of the object calculation (Action-17b) with the necessary adjustments (Action$17 d)$;

- control of receipt of payment (Action-17e) with monitoring of the date of payment receipt (task 17.1);

- control over the qualification data saving (Action-17.1a) with the necessary adjustments (Action-17.1c);

- final control of the glider (Action-17.1b) with the necessary adjustments (Action17.1d).

- automatic generation of the final report (documentation 18.1) on the facility design (Application-3).

At this stage, all the cost data loaded into the glider by the project manager is checked, a count is formed for the object, the profit is calculated and bonuses are assigned.

If the project manager fails to meet the deadlines for the tasks of the business process, the system penalizes him. Each task has such an indicator as "Step amount", according to which the penalty is set.

\section{Research results}

The considered scheme of business processes makes it possible to efficiently organize the project activities.

The system itself gives tasks to the project manager, thereby helping him and preventing the possibility of mistakenly skipping at least one step from the "scheme".

Each task has a deadline, which is monitored by a technical control specialist. For failure to meet the deadlines for the business process, the project manager is deprived of the bonus for the successful completion of the object.

In addition to monitoring deadlines, a technical control specialist monitors the correctness of the project manager's work in the process of conducting a business process, namely:

- the correctness of the technical solutions adopted in the project;

- correct execution of design and working documentation in accordance with GOST 21.101-97 "System of design documentation for construction (SDDC)". Basic requirements for design and working documentation;

- the correctness of the deadlines set by the project manager for conceptual study, development of the design and working documentation sections, passing the examination;

- the correctness of the project data entered into the planner by the project manager (selection of the performers for the design and working documentation development, the cost of wages to workers, passing the state examination, obtaining paid approvals).

\section{Conclusion}

As a result of the engineering introduction by the business processes of organizing the construction work design, the time period for the design estimates preparation is reduced, and the reliability of the work performed increases due to the management tools' digitalization use in project activities.

\section{References}

1. N.D. Koryagin, Statistics and Economics 3, 72-76 (2015)

2. A.V. Nalimova, IOP Conference Series: Materials Science and Engineering 913, 
(2020) iopscience.iop.org/article/10.1088/1757-899X/913/4/042027/pdf.

3. O.A. Fil, V.A. Terentyev, IOP Conference Series: Materials Science and Engineering 262 (1), (2017) iopscience.iop.org/article/10.1088/1757-899X/262/1/012076/pdf.

4. L.N. Ustinova, N.P. Roman, Scientific and technical statements of SPbSPU. Economic Sciences 13 (5), 136-144 (2020)

5. O.A. Fil, IOP Conference Series: Materials Science and Engineering 913, (2020) iopscience.iop.org/article/10.1088/1757-899X/913/2/022048

6. K.E. Salnikov, Finance and Management 4, (2020) nbpublish.com/library_read_article.php?id=34406

7. V.N. Kabanov, Engineering Journal of Don 2, (2018) ivdon.ru/ru/magazine/archive/n2y2018/4879

8. O. Pobegaylov, O. Fil, P. Tchyoubka, Ai-Shamiru A., E3S Web of Conferences 91, (2019) doi.org/10.1051/e3sconf/20199108010

9. V.V. Kostyuchenko, Engineering Bulletin of the Don 4, (2013) ivdon.ru/uploads/article/pdf/IVD_202_Kostuchenko.pdf_8aa0bd7bfe.pdf

10. G.N. Shinkareva, Vestnik MGSU 13 (9) (120), 1090-1105 (2018) 